\title{
Daytime Mouthpiece Ventilation Plus Nighttime Noninvasive Ventilation Improves Quality of Life in Patients With Neuromuscular Disease
}

Respiratory failure due to respiratory muscle dysfunction is a common problem in neuromuscular diseases, ${ }^{1}$ and respiratory muscle weakness can be reversible, relapsing, or progressive. ${ }^{2}$ In amyotrophic lateral sclerosis (ALS), the respiratory muscle dysfunction is not reversible, and respiratory failure is fatal, usually within 5 years. $^{3}$ One method of measuring the decline of respiratory function in patients with ALS is the sniff nasal inspiratory pressure test, which is independent of facial muscle strength and correlates with invasive tests of diaphragm strength and sternocleidomastoid function. ${ }^{4,5}$ The most commonly used measurement, including in clinical trials, is FVC. There is a linear relationship between FVC and ALS functional rating scale score, ${ }^{6}$ but measuring $\mathrm{FVC}$ can be difficult for ALS patients with bulbar dysfunction because the FVC test requires that the patient tightly seal his or her lips around the mouthpiece.

In patients with ALS, noninvasive ventilation should be initiated early. ${ }^{3}$ Progression of the disease leads first to rapid eye movement-related and later also to non-rapid eye movement-related sleep-disordered breathing. The sleepdisordered breathing in patients with ALS or other neuromuscular diseases may be obstructive sleep apnea syndrome. Most patients suffer from alveolar hypoventilation. The resulting nocturnal hypercapnia leads to disturbed sleep architecture, with consecutive nights of decreased sleep quality and efficiency. ${ }^{7}$ In those who do not yet have bulbar dysfunction, noninvasive ventilation extends life, and in those with bulbar dysfunction and spinal onset, noninvasive ventilation improves the quality of life. ${ }^{89}$ Noninvasive ventilation improves daytime hypoventilation in patients with neuromuscular diseases, probably by improving nocturnal hypercapnia and thus restoring central chemoreceptor sensitivity. ${ }^{10,11}$ In this issue of ReSPIRATORY CARE, Khirani et al ${ }^{12}$ report their study of ventilators for mouth-

Dr Czell has disclosed no conflicts of interest.

Correspondence: David C Czell MD, Department of Neurology, Cantonal Hospital Winterthur, Brauerstrasse 15, 8401 Winterthur, Switzerland. E-mail: david.czell@gmx.ch.

DOI: $10.4187 /$ respcare. 03418 piece ventilation in patients with neuromuscular disease. For 30 subjects (mean age $33 \pm 11$ y) with various neuromuscular diseases, the authors used a questionnaire to assess the practice and effects of mouthpiece ventilation. The subjects reported improvements in dyspnea, fatigue, speech, and eating. The improvement of speech and eating may be a side effect because of the improvement of dyspnea and fatigue. Mouthpiece ventilation in patients with

See the Original Study on Page 1329

chronic respiratory failure is often used. ${ }^{13,14}$ Mouthpieces are very useful in adjunct daytime ventilation for patients suffering from neuromuscular diseases who do not have the ability to maintain acceptable diurnal arterial blood gases without frequent intermittent periods of assistance. ${ }^{15}$ During the night while sleeping, most patients use a mask because a mouthpiece is uncomfortable. Most patients who need assistance day and night use a combination of interfaces. ${ }^{15}$ One advantage of the mouthpiece is that it can be mounted close to the head so that the patient can speak after each breath. A second advantage is prevention of air leakage through the mouth, which can occur when using nasal masks. If nasal leakage occurs, nose plugs can be used. ${ }^{13,14,16}$ Disadvantages are the occurrence of orthodontic problems and hypersalivation, which can be very uncomfortable for patients with ALS because hypersalivation occurs often in patients with bulbar symptoms..$^{15}$ Further studies on mouthpiece ventilation in patients with progressive respiratory impairment are needed in the quest to improve the quality of life in patients with neuromuscular disease.

David C Czell MD

Department of Neurology

Cantonal Hospital Winterthur Winterthur, Switzerland

\section{REFERENCES}

1. Oana S, Mukherji J. Acute and chronic respiratory failure. Handb Clin Neurol 2014;119(Can't get issue from record):273-288. 


\section{Combined Ventilation for Neuromuscular Disease}

2. Ozsancak A, D'Ambrosio C, Hill NS. Nocturnal noninvasive ventilation. Chest 2008;133(5):1275-1286.

3. Chiò A, Logroscino G, Hardiman O, Swingler R, Mitchell D, Beghi E et al. Prognostic factors in ALS: a critical review. Amyotroph Lateral Scler 2009;10(5-6):310-323.

4. Morgan RK, McNally S, Alexander M, Conroy R, Hardiman O, Costello RW. Use of sniff nasal-inspiratory force to predict survival in amyotrophic lateral sclerosis. Am J Respir Crit Care Med 2005; 171(3):269-274

5. Bauer M, Czell D, Hartmann S, Goldman B, Müller D, Weber M. Limitations of sniff nasal pressure as an outcome measurement in amyotrophic lateral sclerosis patients in a clinical trial. Respiration 2012;84(4):306-311.

6. Traynor BJ, Zhang H, Shefner JM, Schoenfeld D, Cudkowicz ME. Functional outcome measures as clinical trial endponts in ALS. Neurology 2004;63(10):1933-1935.

7. van Kesteren RG, Kampelmacher MJ. [Mechanical ventilation in neuromuscular diseases: do not start too early, but certainly not too late]. Ned Tijdschr Geneeskd 2000;144(26):1249-1252. Article in Dutch.

8. Aboussouan LS, Khan SU, Meeker DP. Effect of noninvasive ventilation on survival in amyotrophic lateral sclerosis. Ann Intern Med 1997;127(6):450-453.

9. Bourke SC, Tomlinson M, Williams TL. Effects of noninvasive ventilation on survival and quality of life in patients with amyotrophic lateral sclerosis: a randomised controlled trial. Lancet Neurol 2006;5(2):140-147.

10. Annane D, Quera-Salva MA, Lofaso F. Mechanisms underlying effects of nocturnal ventilation on daytime blood gases in neuromuscular diseases. Eur Respir J 1999;13(1):157-162.

11. Turkington PM, Elliott MW. Rationale for the use of noninvasive ventilation in chronic ventilator failure. Thorax 2000;55(5):417423.

12. Khirani S, Ramirez A, Delord V, Leroux K, Lofaso F, Hautot S, et al. Evaluation of ventilators for mouthpiece ventilation in neuromuscular disease. Respir Care 2014;59(9):1329-1337.

13. Bach JR, Alba AS, Saporito LR. Intermittent positive pressure ventilation via the mouth as an alternative to tracheostomy for 257 ventilator users. Chest 1993;103(1):174-182.

14. Boitano LJ, Benditt JO. An evaluation of home volume ventilators that support open-circuit mouthpiece ventilation. Respir Care 2005; 50(11):1457-1461.

15. Robert D, Argaud L. Clinical review: long-term noninvasive ventilation. Crit Care 2007;11(2):210.

16. Hess D. Noninvasive ventilation in neuromuscular disease: equipment and application. Respir Care 2006;51(8):896-911; discussion 911-912. 